\title{
First round to Amgen in EPO battle
}

The patent infringement lawsuit between Amgen (Thousand Oaks, CA) and Transkaryotic Therapies (TKT; Cambridge, MA), to determine which has the US right to exclude others from "making, importing, using or selling" erythropoietin (EPO), is expected to commence this month. Amgen claimed a small victory in the three-year saga at the end of March when US District Judge William Young supported broad interpretation of its patent claims and several key genomic terms in a Markman hearing. However, some of the rulings could end up working against Amgen, if it fails to prove them in the actual trial.

Markman hearings are held before a patent infringement trial to establish legal definitions of technical terms, which the court then uses in a trial to determine what evidence may or may not be considered when construing the meaning and scope of an invention described in a patent claim.

The current case revolves around EPO, a glycoprotein produced by the kidneys to stimulate red blood cell production. It is the active component in Amgen's blockbuster drug Epogen, US sales of which rose $21 \%$ to $\$ 1.8$ billion in 1999. Amgen accused TKT of infringing five US patents, which claim EPO and its pharmaceutical composition, the process of preparing a biologically active EPO, and the host vertebrate cells in which EPO can be produced.

Amgen's process patent describes the production of its erythropoietin product, Epogen, by expression of the cloned human EPO cDNA sequence, by placing the simian viral DNA promoter (SV40) adjacent to the target gene, in vertebrate or mammalian cell lines, such as Chinese hamster ovary (CHO) cells. TKT, on the other hand, produces its gene-activated erythropoietin (GA-EPO) in human cells by "turning on" normally quiescent genes using a promoter DNA sequence inserted upstream of the target gene.

During the hearing, TKT and its partner Aventis Pharma (previously Hoechst Marion Roussel) argued that Amgen's patent claiming the expression of EPO in "vertebrate" or "mammalian" host cells does not encompass "human" cells, stating that Amgen's patent, written in the early 1980s, does not teach a method "that one skilled in the art" could produce EPO in human cells. However, Young ruled against TKT, agreeing with Amgen that patent claims to the protein expressed in "vertebrate or mammalian cells" could extend to expression in all mammals, including humans.

Debra Robertson is a freelance writer working in San Diego, CA.
However, this ruling could turn out to be a double-edged sword for Amgen during the infringement trial itself if the definition of the invention is broader than the teaching of the invention described in the actual patent text. It may require Amgen to prove that its invention allows the expression of EPO in human cellssomething TKT attorneys stressed that Amgen was unable to do at the time of the patent filing.

In the hearing, TKT also tried to distinguish its process of producing GA-EPO from Amgen's claimed method by focusing on the interpretation of language describing the promoter sequences. Wording, including "nonhuman DNA sequences that control transcription" or "transcription control of DNA sequences, other than human erythropoietin transcription control sequences," found in two of Amgen's patent claims was defined by Young as sequences that are "not part of the human genome," including the simian promoter described in the patent. TKT had proposed that "nonhuman" be defined as "not originating from the human genome" because it uses a viral promoter that the company may try to argue arises from the human genome.

Young also opted for a broad interpretation when defining the location of the promoter: TKT had argued that Amgen's claims are limited to cases where the promoter is directly adjacent to the target gene, rather than extending to include anywhere "upstream."

Without ruling, Judge Young also heard arguments from Amgen that TKT's GA-EPO is chemically and functionally the same as the 166-amino acid mature EPO amino acid sequence claimed in Amgen's patent. TKT counters that it produces a 165 -amino acid protein and claims that it differs from that described by Amgen. Moreover, TKT is likely to cite experiments at trial that demonstrate that Amgen's patents do not teach the expression of human EPO: TKT claims that a EPO expressed using Amgen's method produces a 166-amino acid form in the nonhuman, baby hamster kidney (BHK) cell line, whereas a 165 -amino acid $\mathrm{EPO}$ is produced in the $\mathrm{CHO}$ cell line.

Meanwhile, TKT's counterattack to the infringement suit centers around the validity of the EPO patents. TKT argues in a parallel case that Amgen engaged in "inequitable conduct" in gaining some of its patents, accusing Amgen of misleading the patent office about the different chemical properties of the drug relating to EPO produced in the vertebrate cell lines, BHK cells, and $\mathrm{CHO}$ cells, and withholding key information about prior clinical trials involving EPO. TKT also asserts that Amgen's claims to the protein itself are invalid: TKT cites 1976 prior art describing isolation and biological activity of EPO before the filing of Amgen's patent application in the early 1980s. The 1976 disclosure comes from Eugene Goldwater's laboratory at the University of Chicago, where the isolation of small amounts of EPO from 2,500 quarts of urine and its limited use in humans was described.

Amgen shares rose 9\% or $\$ 5.81$ to close at $\$ 60.38$ on Nasdaq while TKT shares fell $\$ 7.88$ closing at $\$ 70.25$, the first day after the Markman hearing. A loss for Amgen could markedly slow the company's $20 \%$ profit growth, as Epogen currently accounts for half of the company's revenues. But the overall impact will depend on the success of Amgen's other drugs, including novel erythropoiesis-stimulating protein (NESP) - a chemically distinct and more potent form of Epogen expected to receive FDA approval later this year. A judgment against the smaller TKT, however, should not put the company out of business as TKT may have a better chance of retaining the rights to sell GA-EPO in Europe, which has stricter patent requirements.

Debra Robertson 